Karakteristik Bangkitan Perjalanan Perumahan Kelas Menengah Berbasis Rumah Tangga (Suryanto) 


\title{
KARAKTERISTIK BANGKITAN PERJALANAN PERUMAHAN KELAS MENENGAH BERBASIS RUMAH TANGGA
}

\author{
Oleh: Suryanto ${ }^{1}$ \\ E-mail:suryantonandan@gmail.com
}

\begin{abstract}
ABSTRAK : Perlunya pendataan dan analisis setiap saat dan tempat mengenai jumlah perjalanan yang berasal dari kawasan pemukiman yang berupa perumahan beserta faktor-faktor yang mempengaruhi. pendataan dan analisis tersebut diperlukan setiap saat dan tempat karena hampir semua unsur-unsur atau faktor-faktor yang mempengaruhi jumlah perjalanan merupakan fungsi tempat dan waktu. Unsur-unsur yang merupakan variabel atau peubah terdiri dari jumlah pemilikan kendaraan, pendapatan, dan ukuran rumah tangga (karakteristik rumah tangga). Metode analisis regresi dipakai untuk pendekatan model karena data yang diperlukan tidak banyak, dan terdapatnya uji statistik untuk menguji keabsahan model. Dari hasil Proses model analisis korelasi dengan metode analisis langkah demi langkah, model terbaik yang dihasilkan adalah Karakteristik bangkitan perjalanan perumahan klas menengah berbasis rumah tangga, dengan contoh Bangkitan Pergerakan yang berasal dari Perumnas Condongcatur Kecamatan Depok Kabupaten Sleman Propinsi Daerah Istimewa Yogyakarta, dipengaruhi oleh Ukuran Rumah Tangga, Pemilkan Kendaraan, dan Pendapatan.
\end{abstract}

Kata kunci : bangkitan perjalanan, berbasis rumah tangga, perumahan klas menengah, regresi linear

\section{PENDAHULUAN}

Pendataan dan analisis setiap saat dan tempat mengenai jumlah perjalanan yang berasal dari kawasan pemukiman (yang berupa perumahan) beserta faktor-faktor yang mempengaruhi diperlukan, karena hampir semua unsur-unsur atau faktor-faktor yang mempengaruhi jumlah perjalanan merupakan fungsi tempat dan waktu. Unsur-unsur yang merupakan variabel atau peubah terdiri dari jumlah penghuni, jumlah pemilikan kendaraan, luas bangunan atau tipe rumah, pendapatan, struktur rumah tangga, dan ukuran rumah tangga (karakteristik rumah tangga). Dengan adanya peubah-peubah tersebut diperlukan analisis untuk mengetahui besar pengaruhnya. Sebagai contoh dalam analisis ini adalah Perumnas Condongcatur Kecamatan Depok Kabupaten Sleman Propinsi Daerah Istimewa Yogyakarta dan Perumahan Armada Estate Kota Magelang Propinsi Jawa Tengah, mengingat masyarakat pada perumahan ini mempunyai karakteristik sosialekonomi yang relatif homogen. Permasalahan dalam analisis ini dapat dirumuskan :

1) Menentukan peubah-peubah dari model bangkitan perjalanan yang signifikan.

2) Membandingkan dan menganakisis model bangkitan perjalanan berbasis rumah tangga untuk dua perumahan klas menengah sehingga diketahui karakteristiknya.

Pemodelan jumlah perjalanan yang ditimbulkan atau bangkitan perjalanan dapat digunakan untuk kontrol kesesuaian antara supplay (fasilitas jalan) dengan demand (jumlah perjalanan) dan design (prediksi) jumlah perjalanan pada masa yang akan datang. Analisis bangkitan perjalanan ini bertujuan :

1) Menghasilkan model hubungan yang mengaitkan parameter jumlah pergerakan yang meninggalkan perumahan klas menengah dengan karakteristik rumah tangganya, dan membandngkan model bangkitan perjalanan untuk dua perumahan klas menengah sehingga dapat diketahui karakteristiknya

1) adalah staf pengajar Program Studi Teknik Sipil Universitas Cokroaminoto Yogyakarta 
2) Bangkitan pergerakan ini meramalkan jumlah pergerakan yang akan dilakukan oleh seseorang pada setiap zona asal dengan menggunakan data rinci mengenai tingkat bangkitan pergerakan, atribut sosioekonomi, serta maksud perjalanan.

3) Mengidentifikasi korelasi antara besarnya pergerakan dengan berbagai peubah, dan setiap peubah tersebut juga saling berkorelasi. Kajian ini biasanya menggunakan data berbasis rumah tangga untuk memodel besarnya pergerakan yang terjadi (bangkitan).

4) Tujuan akhir perencanaan bangkitan pergerakan adalah menaksir setepat mungkin bangkitan pergerakan pada masa sekarang, yang akan digunakan untuk meramalkan pergerakan pada masa mendatang.

\section{TINJUAN PUSTAKA}

Perkiraan pembangkit perjalanan umumnya didasarkan atas proyeksi tata guna lahan dan aktivitas ekonomi ; misalnya, perumahan atau lahan terbuka yang akan diubah menjadi perumahan dan tata guna lahan lainnya akan menghasilkan sejumlah perjalanan tertentu selama jam-jam tertentu pula. Perjalanan ini diketahui dari survai O-D (asaltujuan) atau data lainnya seperti yang dikumpulkan dalam studi keadaan yang serupa. Selain itu, perkiraan dibuat berdasarkan pembangkit perjalanan akibat kegiatan-kegiatan seperti bekerja, berbelanja, pendidikan, dan rekreasi. Perkiraan ini kemudian dapat dinyatakan sebagai tingkat perjalanan (trip rates) atau dalam bentuk persamaan (Oglesby dan Hicks, 1982). Bangkitan perjalanan/pergerakan menurut Miro (2005) meliputi:

1) Basis perjalanan, merupakan tempat perjalanan diawali dan tempat perjalanan diakhiri. Perjalanan adalah pergerakan satu arah dari zona asal ke zona tujuan dengan maksud tertentu. Perjalanan berbasiskan rumah, merupakan perjalanan yang salah satu atau kedua dari asal-tujuannya adalah rumah.

2) Pendekatan analisis, yaitu pendekatan yang dipakai dalam mengestimasi kebutuhan perjalanan pada bangkitan perjalanan. Pendekatan disagregat, merupakan pendekatan yang dilakukan per individu dengan memahami langsung atribut-atribut elemen yang lebih kecil seperti : faktor-faktor yang berpengaruh menimbulkan perjalanan tetapi melekat pada diri orang yang melakukan perjalanan (trip maker) diantaranya : pendapatan pelaku perjalanan, jumlah kendaraan yang dimiliki, struktur dan ukuran rumah tangga, dan lain-lain. Pendekatan ini sangat erat kaitannya dengan perjalanan berbasiskan rumah.

3) Metode analisis, yaitu dengan metode analisis regresi linear (regresi linear sederhana atau regresi linear berganda).

Model pembangkit perjalanan menurut Morlok (1978) adalah :

1) Maksud perjalanan-berdasarkan-rumah, di mana tempat asal atau tujuan perjalanan adalah dari atau menuju rumah, dan perjalanan-perjalanan lainnya yang tidak bersangkut paut dengan rumah. Kedua, terdapat konsep-konsep mengenai tempat asal dan tujuan perjalanan. Akhirnya, terdapat konsep mengenai zona tarikan (attraction zone) dan zona pengadaan/produksi (production zone). Zona pengadaan/produksi adalah lokasi rumah pada semua perjalanan-berdasarkanrumah, baik sebagai tempat asal maupun tempat tujuan, dan merupakan zona asal pada perjalanan yang bukan berdasarkan rumah (non home-based-trips). Konsep dan definisi perjalanan ini penting karena cara yang dipakai dalam memperkirakan jumlah perjalanan ada yang berdasarkan rumah dan ada yang tidak berdasarkan rumah. Pengadaan/produksi perjalanan-berdasarkan-rumah didasarkan pada karakteristik rumah yang merupakan tempat asal atau tujuan perjalanan, sedangkan pengadaan perjalanan yang bukan-berdasarkan-rumah didasarkan pada karakteristik zona asal. 
2) Metode lainnya yang biasa digunakan untuk estimasi perjalanan residensial adalah analisi regresi, yaitu suatu metode yang dipakai untuk memperkirakan nilai-nilai terbaik bagi sejumlah parameter pada hubungan matematis tertentu di antara dua variable atau lebih.

3) Jumlah perjalanan dibagi-bagi sesuai dengan maksud, dan model-model yang berbeda dikembangkan untuk masing-masing maksud perjalanan. Biasanya jumlah perjalanan yang dibangkitkan didasarkan pada jenis tata guna lahan, dimana terdapat perbedaan-perbedaan untuk kantor, industri, perdagangan, toko-toko, pendidikan, bangunan umum, ruang terbuka, transportasi dan utilitas, dan lahan kosong.

4) Untuk setiap klasifikasi kegiatan dan maksud perjalanan, prosedur yang biasa adalah memperkirakan tingkat perjalanan untuk kelompok tertentu, yang didasarkan pada pembagian jumlah perjalanan yang diamati untuk maksud tersebut dengan ukuran tertentu terhadap kegiatan total di daerah tata guna lahan yang tertentu pula. Pada umumnya ukuran dari suatu kegiatan adalah besarnya sarana, seperti ribuan feet (kaki) kuadrat atau jumlah pekerja.

5) Model pembangkit perjalanan sering dipakai untuk memperkirakan jumlah perjalanan total yang berasal dari dan menuju ke daerah-daerah pengembangan/pembangunan utama, seperti pusat perbelanjaan yang baru, pelabuhan udara, dan kawasan industri. Pada waktu fasilitas tadi dibangun atau ditingkatkan, harus dipertimbangkan cukup tidaknya fasilitas transportasi yang tersedia (terutama jalan-jalan), di daerah sekitar fasilitas tersebut. Dengan memperkirakan jumlah perjalanan keluar-masuk daerah tersebut, daya tampung jalan-jalan di sekitarnya akan dapat diperkirakan, dan rencana-rencana yang sesuai dapat dibuat untuk setiap perubahan yang diperlukan. Sering kali taksiran diadakan untuk arah lalu-lintas keluar-masuk daerah tersebut, atau data yang sudah ada juga dapat digunakan untuk memperkirakan perkembangan yang bakal terjadi.

\section{LANDASAN TEORI}

Hal-hal yang berkaitan dengan pemodelan bangkitan pergerakan menurut Tamin (1997, 2003) adalah:

1) Bangkitan pergerakan untuk manusia. Faktor berikut dipertimbangkan pada beberapa kajian yang telah dilakukan :

a) Pendapatan

b) Pemilikan kendaraan

c) Struktur rumah tangga

d) Ukuran rumah tangga

e) Nilai lahan

f) Kepadatan daerah pemukiman

g) Aksesibilitas

Empat faktor pertama (pendapatan, pemilikan kendaraan, struktur rumah tangga, ukuran rumah tangga) telah digunakan pada beberapa kajian bangkitan pergerakan. Untuk perumahan, peubah rumah tangga yang paling signifikan adalah jumlah penghuni, jumlah pemilikan kendaraan, dan luas bangunan atau tipe rumah,.sedangkan nilai lahan dan kepadatan daerah pemukiman hanya sering dipakai untuk kajian mengenai zona.

2) Analisi regresi. Metode analisis regresi akan digunakan untuk menghasilkan hubungan dalam bentuk numerik dan untuk melihat bagaimana dua (regresi sederhana) atau lebih (regresi berganda) peubah saling terkait. Beberapa asumsi statistik harus dipertimbangkan sebelum menggunakan metode analisis regresi sebagai berikut ini :

74 Karakteristik Bangkitan Perjalanan Perumahan Kelas Menengah Berbasis Rumah Tangga (Suryanto) 
a) Peubah tidak bebas adalah merupakan fungsi linear dari peubah bebas. Jika hubungannya tidak linear, data kadang-kadang harus ditransformasikan terlebih dahulu agar menjadi linear. Batasan ini mempunyai implikasi yang lain terhadap analisis residual.

b) Peubah, terutama peubah bebas, adalah tetap atau telah terukur tanpa galat.

c) Tidak ada korelasi antara peubah bebas.

d) Variansi dari peubah tidak bebas terhadap garis regresi adalah sama untuk semua nilai peubah tidak bebas.

e) Nilai peubah tidak bebas harus tersebar normal atau minimal mendekati normal. Metode analisis regresi dipakai untuk pendekatan model karena data yang diperlukan tidak banyak, dan terdapatnya uji statistik untuk menguji keabsahan model.

\section{METODE PENELITIAN}

1) Peubah dalam penelitian

a) Peubah tidak bebas : bangkitan perjalanan (jumlah perjalanan)

b) Peubah bebas: .

ukuran rumah tangga (jumlah penghuni), pemilikan kendaraan, pendapatan, luas bangunan atau tipe rumah.

2) Pendekatan yang digunakan

Pendekatan kuantitatif dari bangkitan perjalanan berbasis rumah dengan pendekatan disagregat (individu) menggunakan analisis regresi linear.

a) Teknik pengumpulan data

Metode yang digunakan adalah metode sampel, yaitu mengumpulkan data dan informasi dengan jalan mencatat sebagian kecil objek pengamatan yang merupakan bagian dari populasi secara keseluruhan. Cara yang dilakukan dalam penarikan besarnya sampel adalah penarikan secara acak dan bertingkat (stratified random sampling) yang tujuannya agar seluruh objek pada masingmasing tingkat (strata) dapat mewakili populasi, dan dengan demikian dapat pula memiliki peluang yang sama untuk dipilih. Jumlah sampel untuk cara ini, biasanya ditetapkan sebesar $10 \%$ dari populasi seperti rumus berikut :

$$
N=10 \% P
$$

dengan adalah $\mathrm{N}$ adalah sampel, $\mathrm{P}$ adalah populasi.

Perumahan Condong Catur Kelurahan Condong Catur Kecamatan Depok Kabupaten Sleman Propinsi Daerah Istimewa Yogyakarta dihuni oleh 1219 rumah tangga (1998), sedangkan Perumahan Armada Estate Kelurahan Kramat Kecamatan Megelang Utara Kota magelang Propinsi Jawa tengah dihuni oleh 414 kepala keluarga (KK). Untuk sampel penelitian masing-masing perumahan diambil 150 rumah tangga.

i) Data primer, merupakan data-data yang langsung dicari dan dikumpulkan oleh peneliti ke objek pengamatannya dan cara pengumpulannya dengan menggunakan alat bantu daftar pertanyaan (kuesioner), yang berupa karaktristik (atribut) rumah tangga.

ii) Data sekunder, merupakan data atau informasi yang diperoleh dari Badan Pusat Statistik Kabupaten Sleman, berupa karakteristik zona.

b) Proses pengumpulan data

Metode survei yang digunakan diklasifikasikan pada metode langsung, surveyor langsung terjun ke lapangan untuk mendapatkan data-data dan informasi dengan memakai peralatan daftar kuesioner, yaitu dengan metode wawancara rumah tangga (home interview/HI) : 
i) Survei ini dilaksanakan di rumah-rumah penduduk pada kawasan-kawasan pemukiman yang sangat potensial menimbulkan perjalanan. Oleh karena itu, data yang diperoleh dari survei ini berguna sebagai input basis data untuk bangkitan perjalanan, karena zona pemukiman yang memproduksi perjalanan.

ii) Objek survei ini adalah personil yang mendiami rumah-rumah di kawasan perumahan. Selanjutnya dianalisis karakteristik objek yang akan dijadikan variabel/faktor penyebab terproduksinya perjalanan dari zona pemukiman.

iii) Cara pelaksanaan survei ini dengan mengambil sampel yang mewakili rumahrumah, dengan besar sampel $10 \%$.

iv) Alat kelengkapan survei ini salah satunya adalah daftar pertanyaan, sedangkan teknis pelaksanaannya adalah didatangi langsung oleh surveyor.

\section{c) Cara analisis (Analisis Korelasi)}

Secara umum proses pemodelan bangkitan pergerakan dengan menggunakan metode regresi-linear dapat dilihat pada Gambar 1.

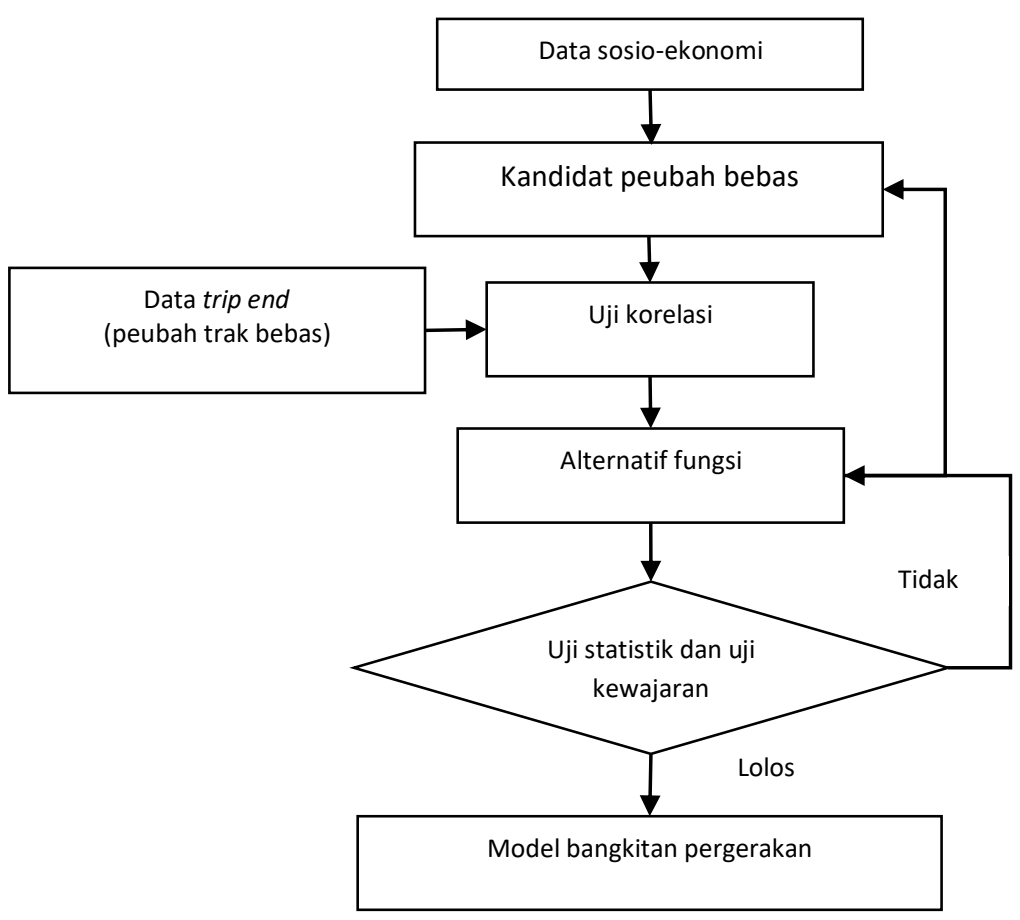

Gambar 1. Proses kalibrasi dan pengabsahan model analisis-korelasi

(Tamin, 2003)

\section{2) Model analisis regresi-linear-berganda}

Konsep ini merupakan pengembangan lanjut dari kasus yang mempunyai lebih banyak peubah bebas dan parameter $\mathrm{b}$. Hal ini sangat diperlukan dalam realita yang menunjukkan bahwa beberapa peubah tata guna lahan secara simultan ternyata mempengaruji bangkitan pergerakan. Bentuk umum metode analisis regresi-linear-berganda :

$$
Y=A+B_{1} X_{1}+B_{2} X_{2}+\ldots+B_{i} X_{i}
$$

$$
\begin{array}{ll}
\text { dengan: } & \\
Y & =\text { peubah tidak bebas } \\
X_{1} \ldots X_{i} & =\text { peubah bebas } \\
A & =\text { konstanta regresi } \\
B_{1} \ldots B_{i} & =\text { koefisien regresi }
\end{array}
$$

76 Karakteristik Bangkitan Perjalanan Perumahan Kelas Menengah Berbasis Rumah Tangga (Suryanto) 
Nilai $A, B_{1}, \ldots, B_{i}$ dapat dihitung dengan menggunakan analisis regresilinear-berganda, yaitu menyelesaikan $(i+1)$ buah persamaan linear simultan.

analisis regresi-linear-berganda adalah suatu metode statistik. Untuk menggunakannya, terdapat beberapa asumsi yang perlu diperhatikan :

a) Nilai peubah, khususnya peubah bebas, mempunyai nilai tertentu atau merupakan nilai yang didapat dari hasil survei tanpa kesalahan yang berarti :

b) Peubah tidak bebas $(Y$ ) harus mempunyai hubungan korelasi linear dengan peubah bebas $(X)$. Jika hubungan tersebut tidak linear, transformasi linear harus dilakukan, meskipun batasan ini akan mempunyai implikasi lain dalam analisis residual.

c) Efek peubah bebas pada peubah tidak bebas merupakan penjumlahan, dan harus tidak ada korelasi yang kuat antara sesama peubah bebas.

d) Variansi peubah tidak bebas terhadap garis regresi harus sama untuk semua nilai peubah bebas.

e) Nilai peubah tidak bebas harus tersebar normal atau minimal mendekati normal.

f) Nilai peubah bebas sebaiknya merupakan besaran yang relatif mudah diproyeksikan.

Beberapa hal lain yang harus diperhatikan :

a) Multikolinear. Hal ini terjadi karena adanya hubungan linear antar-peubah. Pada kasus ini, beberapa persamaan yang mengandung $Ъ$ tidak saling bebas dan tidak dapat dipecahkan secara unik.

b) Parameter b yang dibutuhkan. Untuk memutuskan hal ini, beberapa faktor harus dipertimbangkan :

i) Apakah ada alasan teori yang kuat sehingga harus melibatkan peubah itu atau apakah peubah itu penting untuk proses uji dengan model tersebut?

ii) Apakah peubah itu signifikan dan apakah tanda koefisien parameter yang didapat sesuai dengan teori atau intuisi ?

iii) Jika diragukan, peubah itu dihilangkan dan proses regresi dilakukan lagi untuk melihat efek dibuangnya peubah itu terhadap peubah lainnya yang masih digunakan oleh model tersebut. Jika ternyata tidak terlalu terpengaruh, peubah itu dibuang saja sehingga kita mendapatkan model yang lebih sederhana dan dapat ditaksir secara lebih tepat.

c) Koefisien determinasi $\mathbf{R}^{2}$. Tambahan peubah $\mathrm{b}$ biasanya meningkatkan nilai $R^{2}$, untuk mengatasinya digunakan nilai $R^{2}$ yang telah dikoreksi.

d) Koefisien korelasi r. Koefisien korelasi ini digunakan untuk menentukan korelasi antara peubah tidak bebas dengan peubah bebas atau antara sesama peubah bebas. Nilai $r=0$ menyatakan tidak ada korelasi antarpeubah

e) Uji t-test. Uji t-test dapat digunakan untuk 2 (dua) tujuan, yaitu untuk menguji sigmifikansi nilai koefisien korelasi ( $r$ ) dan untuk menguji sigmifikansi nilai koefisien regresi. Setiap peubah yang mempunyai koefisien regresi yang tidak signifikan secara statistik harus dibuang dari model.

3) Model regresi berbasis rumah tangga.

Keragaman dalam suatu zona (intrazona) mungkin bisa dikurangi dengan memperkecil luas zona, apalagi jika zona tersebut homogen. Akan tetapi, zona yang lebih kecil juga akan mempunyai keragaman yang cukup besar dan mempunyai 2 (dua) konsekuensi :

a) Model menjadi lebih mahal dalam hal pengumpulan data, kalibrasi, dan operasi:

b) Galat sampel menjadi lebih tinggi. 
Karena itu, sangatlah masuk akal jika kita merumuskan model yang tidak berdasarkan batas zona. Pada penerapan pemodelan berbasis rumah tangga, data setiap rumah dipakai sebagai masukan data vektor sehingga semua fluktuasi mengenai ciri rumah tangga dan perilakunya dapat semuanya dipertimbangkan dalam model tersebut. Proses kalibrasi menggunakan metode langkah-demilangkah, menguji setiap peubah secara bergantian sampai didapatkan model terbaik.

\section{Hasil Penelitian dan Pembahasan}

Uji kecukupan data

$$
N=\frac{C V^{2} Z_{\alpha}^{2}}{E^{2}}
$$

dengan :

$\mathrm{N}=$ jumlah data minimum

$C V=$ koefisien - var iasi $=\frac{\text { simpangan }- \text { baku }}{\text { rata }- \text { rata }}$

$\mathrm{CV}=$ diambil 0.3

$\mathrm{E}=$ tingkat akurasi $=0.05$

$Z_{\alpha}=$ nilai variansi untuk tingkat kepercayaan $\alpha$ yang diinginkan

$\alpha=95 \%$ maka $Z 95 \%=1.645$

$\mathrm{N}=\left(0.3^{*} 1.645 / 0.05\right)^{\wedge} 2=97.4169$

Data penelitian yang diambil 150

Proses model analisis korelasi dengan metode analisis langkah demi langkah

Tahap 1:Penentuan parameter sosio-ekonomi :
Peubah bebas:
X1 = Ukuran Rumah Tangga
$\mathrm{X} 2$ = Pemilkan Kendaraan
$\mathrm{X} 3$ = Pendapatan
Peubah bebas :
$\mathrm{Y}=$ Bangkitan Pergerakan

Uji korelasi

Uji statistik ini harus dilakukan untuk memenuhi persyaratan model matematis : sesama peubah bebas tidak boleh saling berkorelasi, sedangkan antara peubah tidak bebas dengan peubah bebas harus ada korelasi yang kuat (baik positif maupun negatif).

Koefisien koelasi mempunyai nilai $r=(-1 \leq r \leq+1)$

Nilai $r$ yang mendekati -1 mempunyai arti bahwa kedua peubah tersebut saling berkorelasi negatif (peningkatan nilai salah satu peubah akan menyebabkan penurunan nilai peubah lainnya). Sebaliknya, jika nilai $r$ yang mendekati +1 mempunyai arti bahwa kedua peubah tersebut saling berkorelasi positif (peningkatan nilai salah satu peubah akan menyebabkan peningkatan nilai peubah lainnya) Jika nilai $r$ mendekati 0 , tidak terdapat korelasi antara kedua peubah tersebut.

Tabel 1 Koefisien koelasi antar peubah

78 Karakteristik Bangkitan Perjalanan Perumahan Kelas Menengah Berbasis Rumah Tangga (Suryanto) 


\begin{tabular}{|l|c|c|}
\hline & Perum Codong Catur & Perum Armada Estate \\
\hline r YX1 & $\mathbf{0 . 7 3 3 7}$ & 0.0175 \\
\hline r X2X3 & 0.5682 & -0.0269 \\
\hline r YX3 & 0.2425 & 0.2477 \\
\hline r YX2 & 0.3150 & -0.1230 \\
\hline r X1X2 & $\mathbf{0 . 3 7 8 6}$ & 0.0032 \\
\hline$r$ X1X3 & $\mathbf{0 . 2 8 6 9}$ & 0.0709 \\
\hline
\end{tabular}

Tahap 2 : Melakukan analisis regresi-linear-berganda dengan semua peubah bebas terpilih untuk mendapatkan nilai koefisien determinasi serta nilai konstanta dan koefisien regresinya.

Untuk menguji keberartian regresi digunakan statistik $F$ yang ditentukan dengan :

$$
\mathrm{F}=\frac{\mathrm{R}^{2} / \mathrm{k}}{\left(1-\mathrm{R}^{2}\right) /(\mathrm{n}-\mathrm{k}-1)}
$$

dengan $\mathrm{R}^{2}$ adalah koefisien determinasi, $\mathrm{k}$ adalah banyak variabel bebas, $\mathrm{n}$ adalah ukuran sampel, dk pembilang adalah $k$, dan dk penyebut adalah ( $n-k-1)$

Untuk analisis regresi Bangkitan Perjalanan dari Perumahan Condong Catur DIY diperoleh $F$ statistik $=57.1640$. Dari daftar distribusi $F$ dengan dk pembilang $=k=3$ dan dk penyebut $=(n-k-1)=150-3-1=146$ didapat $\operatorname{FINV}(0.05,3,(150-3-1))=2.6666$. Melihat $F$ statistik $=57.1640$ lebih besar dari $F$ tabel $=2.6666$, kesimpulannya adalah bahwa regresi linear ganda $Y$ atas $X 1, X 2$, dan $X 3$ bersifat nyata. Regresi $Y^{\wedge}$ secara berarti dapat digunakan untuk prediksi rata-rata $\mathrm{Y}$ apabila $\mathrm{X} 1, \mathrm{X} 2$, dan X3 diketahui. 
Vol. I No.2, Agustus 2019

Tabel 2. Hasil Analisis Regresi Bangkitan Perjalanan

\begin{tabular}{|c|c|c|c|c|c|c|c|c|c|c|c|c|}
\hline \multicolumn{13}{|c|}{ Regression Output Bangkitan Perjalanan dari Perumahan Condong Catur DIY: } \\
\hline Peubah Bebas & $\mathrm{X} 1$ & $\mathrm{X} 2$ & X3 & $\mathrm{X} 1$ & $\mathrm{x} 2$ & $\mathrm{X} 2$ & $\mathrm{X} 3$ & $\mathrm{X} 3$ & $\mathrm{X} 1$ & $\mathrm{X} 1$ & $\mathrm{x} 2$ & $\mathrm{x} 3$ \\
\hline Constant & \multicolumn{3}{|l|}{0.4903} & \multicolumn{2}{|l|}{0.5259} & \multicolumn{2}{|l|}{2.7969} & \multicolumn{2}{|l|}{0.4622} & 0.5361 & 3.0114 & 2.7764 \\
\hline Std Err of $Y$ Est & \multicolumn{3}{|l|}{0.5514} & \multicolumn{2}{|l|}{0.5497} & \multicolumn{2}{|l|}{0.7666} & \multicolumn{2}{|l|}{0.5500} & 0.5488 & 0.7665 & 0.7836 \\
\hline R Squared & \multicolumn{3}{|l|}{0.5401} & \multicolumn{2}{|l|}{0.5399} & \multicolumn{2}{|l|}{0.1052} & \multicolumn{2}{|l|}{0.5394} & 0.5383 & 0.0992 & 0.0588 \\
\hline No. of Observations & \multicolumn{3}{|l|}{150} & \multicolumn{2}{|l|}{150} & \multicolumn{2}{|l|}{150} & \multicolumn{2}{|l|}{150} & 150 & 150 & 150 \\
\hline Degrees of Freedom & \multicolumn{3}{|l|}{146} & \multicolumn{2}{|l|}{147} & \multicolumn{2}{|l|}{147} & \multicolumn{2}{|l|}{147} & 148 & 148 & 148 \\
\hline X Coefficient(s) & 0.6256 & 0.0336 & 0.00005 & 0.6269 & 0.0431 & 0.2596 & 0.0003 & 0.0001 & 0.6325 & 0.6413 & 0.3124 & 0.0007 \\
\hline Std Err of Coef. & 0.0532 & 0.0703 & 0.00019 & 0.0528 & 0.0599 & 0.0940 & 0.0003 & 0.0002 & 0.0511 & 0.0488 & 0.0774 & 0.0002 \\
\hline F-stat & \multicolumn{3}{|c|}{57.1640} & \multicolumn{2}{|c|}{86.2592} & \multicolumn{2}{|l|}{8.6384} & \multicolumn{2}{|l|}{86.0835} & 172.56 & 16.3017 & 9.2436 \\
\hline $\mathrm{F}$ tabel & \multicolumn{3}{|c|}{2.6666} & \multicolumn{2}{|c|}{3.0576} & \multicolumn{2}{|l|}{3.0576} & \multicolumn{2}{|l|}{3.0576} & 3.0576 & 3.0576 & 3.0576 \\
\hline \multicolumn{13}{|c|}{ Regression Output Bangkitan Perjalanan dari Perumahan Armada Estate Jawa Tengah: } \\
\hline Peubah Bebas & $\mathrm{X} 1$ & $\mathrm{X} 2$ & $\mathrm{X3}$ & $\mathrm{X} 1$ & $\mathrm{X} 2$ & $\mathrm{X} 2$ & X3 & $\mathrm{X} 3$ & $\mathrm{X} 1$ & $\mathrm{X} 1$ & $\mathrm{x} 2$ & X3 \\
\hline Constant & \multicolumn{3}{|l|}{3.3482} & \multicolumn{2}{|l|}{3.9151} & 3.3500 & & 2.9315 & & 3.4821 & 3.9741 & 2.9314 \\
\hline Std Err of $Y$ Est & 1.1404 & & & 1.1725 & & 1.1366 & & 1.1448 & & 1.1775 & 1.1687 & 1.1410 \\
\hline R Squared & 0.0749 & & & 0.0154 & & 0.0749 & & 0.0613 & & 0.0003 & 0.0151 & 0.0613 \\
\hline No. of Observations & 150 & & & 150 & & 150 & & 150 & & 150 & 150 & 150 \\
\hline Degrees of Freedom & 146 & & & 147 & & 147 & & 147 & & 148 & 148 & 148 \\
\hline X Coefficient(s) & 0.0006 & -0.1181 & 0.0004 & 0.0195 & -0.1248 & -0.1181 & 0.0004 & 0.0004 & -0.0001 & 0.0191 & -0.1247 & 0.0004 \\
\hline Std Err of Coef. & 0.0870 & 0.0808 & 0.0001 & 0.0892 & 0.0830 & 0.0805 & 0.0001 & 0.0001 & 0.0873 & 0.0896 & 0.0828 & 0.0001 \\
\hline F-stat & 3.9392 & & & 1.1528 & & 5.9492 & & 4.8037 & & 0.0454 & 2.2723 & 9.6727 \\
\hline $\mathrm{F}$ tabel & 2.6666 & & & 3.0576 & & 3.0576 & & 3.0576 & & 3.0576 & 3.0576 & 3.0576 \\
\hline
\end{tabular}

Tahap 3 : Penentuan parameter yang mempunyai korelasi terkecil terhadap peubah tidak bebasnya dan parameter tersebut dihilangkan. Melakukan kembali analisis regresi-linear-berganda dan mendapatkan kembali nilai koefisien determinasi serta nilai konstanta dan koefisien regresinya.

Tahap 4 : Melakukan kembali tahap (3) satu demi satu sampai hanya tertinggal satu parameter saja. 
Tahap 5 : Mengkaji nilai koefisien determinasi serta nilai konstanta dan koefisien regresi setiap tahap untuk menentukan model terbaik dengan kriteria:

1) Semakin banyak peubah bebas yang digunakan, semakin baik model tersebut.

2) Tanda koefisien regresi (+/-) sesuai dengan yang diharapkan

3) Nilai konstanta regresi kecil (semakin mendekati nol, semakin baik)

Nilai koefisien determinasi $\left(R^{2}\right)$ besar (semakin mendekati satu, semakin baik)

Dari hasil Proses model analisis korelasi dengan metode analisis langkah demi langkah, model terbaik yang dihasilkan adalah :

Bangkitan Perjalanan dari Perumahan Condong Catur DIY

$$
Y=0.4903+0.6256 X 1+0.0336 X 2+0.00005 X 3
$$

dengan $Y$ adalah Bangkitan Pergerakan, $X 1$ adalahUkuran Rumah Tangga, X2 adalah Pemilkan Kendaraan, dan X3 adalah Pendapatan.

\section{Kesimpulan}

Karakteristik bangkitan perjalanan perumahan klas menengah berbasis rumah tangga, dengan contoh Bangkitan Pergerakan yang berasal dari Perumnas Condongcatur Kecamatan Depok Kabupaten Sleman Propinsi Daerah Istimewa Yogyakarta, dipengaruhi oleh Ukuran Rumah Tangga, Pemilkan Kendaraan, dan Pendapatan.

\section{DAFTAR PUSTAKA}

Direktorat Penelitian dan Pengabdian kepada Masyarakat Direktorat Jenderal Pendidikan Tinggi, 2006, Panduan Pengelolaan Hibah Penelitian Pengabdian kepada Masyarakat dan Kreativitas Mahasiswa, Edisi VII, Direktorat Penelitian dan Pengabdian kepada Masyarakat Ditjen Dikti Depdiknas Nasional, Jakarta.

Indriati, E., 2003, Menulis Karya IImiah, Penerbit PT Gramedia Pustaka Utama, Jakarta.

Miro, Fidel, 2005, Perencanaan Transportasi untuk Mahasiswa, Perencana, dan Praktisi, Penerbit Erlangga, Jakarta.

Mochtar, I., B., 2001, Bahan Kuliah Cara Penulisan Laporan Teknik, Jurusan Teknik Sipil, Fakultas Teknik Sipil dan Perencanaan Institut Teknologi Sepuluh Nopember, Surabaya.

Morlok, E., K., 1978, Pengantar dan Perencanaan Teknik Transportasi, Diterjemahkan oleh Johan Kelanaputra Hainim, Penerbit Erlangga, Jakarta.

Sihotang, F., M., F,. 2007, Hubungan antara Luas Wilayah Komersial di Pusat Perbelanjaan Perkotaan dengan Tarikan Perjalanan, Jurnal Teknik Sipil Vol. 4, No. 2, Juli 2007, Jakarta

Sudjana, 1989, Metoda Statistik, Penerbit Tarsito, Bandung.

Tamin, O., Z., 1997, Perencanaan dan Pemodelan Transportasi, Penerbit ITB, Bandung.

Tamin, O., Z., 2003, Perencanaan dan Pemodelan Transportasi Contoh Soal dan Aplikasi, Penerbit ITB, Bandung.

Taaffe, E., J., Gauthier, H., L., dan O'Kelly, M., E., 1996, Geography of Transportation, Prentice Hall, Upper Saddle River, New Jersey.

Walpole, R., E., dan Myers, R., H., 1995, Ilmu Peluang dan Statistika untuk Insinyur dan Ilmuwan, Penerbit ITB, Bandung.

Warpani, Suwardjoko, 1990, Merencanakan Sistem Perangkutan, Penerbit ITB, Bandung. 